\title{
Short-term memory with young children
}

\author{
R. C. Atkinson and D. N. Hansen, STANFORD UNIVERITY
} H. A. Bernbach, UNIVERSITY OF MICHIGAN

\begin{abstract}
Two groups of children, a 4-year old and a 5-year old group, were run in a short-term memory experiment specifically designed to sustain the attention of a young child. The results indicated that the technique was successful in permitting the collection of orderly data from these Ss.
\end{abstract}

\section{Problem}

In recent years there has been an increasing interest in the study of short-term memory (STM) as a fundamental problem in verbal learning (e. g., Melton, 1963; Peterson, 1963). Since most of the STM studies have used adult $\mathrm{Ss}$, it seems desirable to extend the range of research to include data on young children. However, the tedious and uninteresting nature of the typical STM task would make it difficult to sustain the attention of a young child. The experiment described in this paper introduces a more appropriate technique which is based on a children's game, and which makes possible the collection of meaningful STM data from young children.

\section{Method}

Forty children served as Ss in the experiment, all attendees at a child day care center in Oakland, California. There were two experimental groups of $20 \mathrm{Ss}$ each; the groups were specified in terms of age. For Group I, the Ss were $31 / 2$ to 41 /2 years old (mean age 4.16, $\mathrm{SD}=.46$ ); for Group II, the age range was $41 / 2$ to $51 / 2$ years (mean age $5.09, \mathrm{SD}=.41$ ). Each group contained ten boys and ten girls.

The material to be remembered consisted of a set of eleven animal cards; i. e., playing cards containing pictures of familiar animals. On each trial, a subset of eight cards was randomly selected, and these were shown one at a time to S. After each card was shown to $S$, it was placed face down on the table so that after all eight cards were presented, they formed a horizontal row in front of S. After the last card was laid down, a cue card identical to one of the cards presented on that trial was placed face up on the table, and S was asked to turn up the card which he thought matched the cue card. When incorrect, $\mathrm{S}$ continued to turn up cards until he located the correct one.

Each $\mathrm{S}$ was run for 32 trials, and each of the eight presentation positions contained the correct response (i.e., the cue card) four times in the session. The assignment of pictures to serial positions was randomly determined for each trial. First and second choice responses were recorded, as was the latency from presentation of the cue card to the touching of the card chosen for the first choice response.

\section{Results}

Figure 1 presents the proportion of correct responses at each position for the two groups of Ss. Position 1 corresponds to the most recently displayed card, and position 8 to the first card shown on a trial. As expected, the proportion of correct responses at a given position is a decreasing function of the number of items intervening between presentation of the item and its test for recall. Note, also, that there is no evidence of a primacy effect in these data; i.e., positions 7 and 8 do not have a higher probability of correct recall than say positions 5 and 6 . In similar experiments with college students and 10-year olds the curves of Fig. 1 were bow shaped, in-

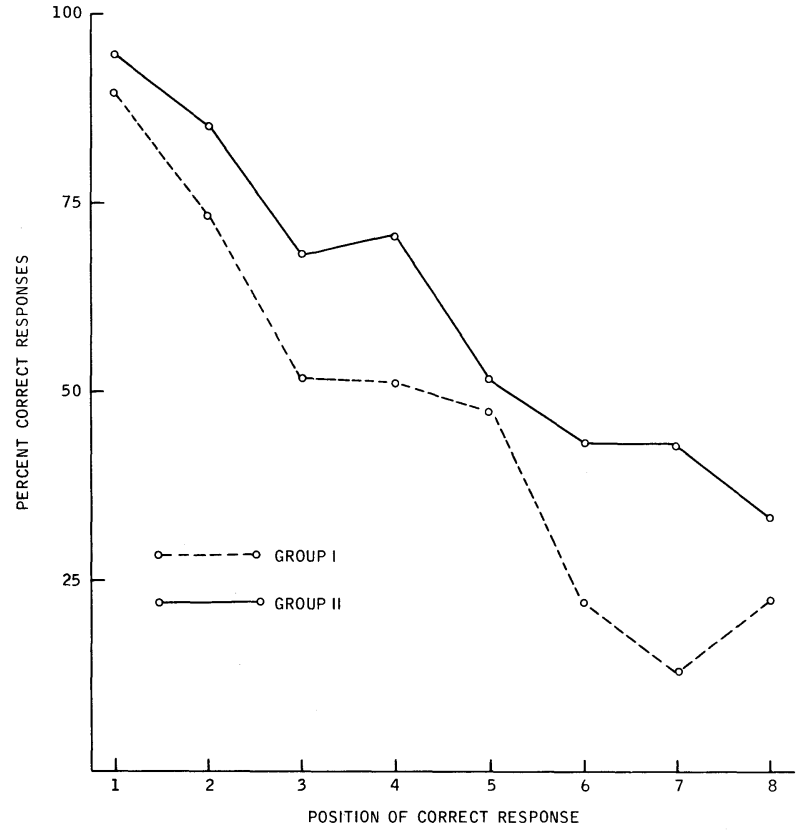

Fig. 1. Percentage frequency of correct first choice responses as a function of the position of the cue card.

Table 1

Frequencies of first-choice responses for each cue card position

\begin{tabular}{|c|c|c|c|c|c|c|c|c|c|}
\hline \multirow{2}{*}{ Group } & \multirow{2}{*}{$\begin{array}{l}\text { Correct } \\
\text { Response }\end{array}$} & \multicolumn{8}{|c|}{ Response Made } \\
\hline & & 1 & 2 & 3 & 4 & 5 & 6 & 7 & 8 \\
\hline \multirow{8}{*}{$I$} & 1 & 71 & 3 & 3 & 0 & 0 & 0 & 0 & 1 \\
\hline & 2 & 3 & 60 & 10 & 3 & 2 & 1 & 1 & 0 \\
\hline & 3 & 7 & 13 & 43 & 11 & 5 & 0 & 0 & 1 \\
\hline & 4 & 1 & 5 & 19 & 42 & 11 & 1 & 0 & 1 \\
\hline & 5 & 1 & 3 & 8 & 27 & 37 & 1 & 1 & 2 \\
\hline & 6 & 2 & 4 & 2 & 11 & 38 & 18 & 3 & 2 \\
\hline & 7 & 2 & 3 & 3 & 10 & 9 & 38 & 12 & 3 \\
\hline & 8 & 1 & 2 & 3 & 8 & 7 & 23 & 19 & 17 \\
\hline \multirow{8}{*}{ II } & 1 & 76 & 0 & 0 & 1 & 1 & 1 & 0 & 1 \\
\hline & 2 & 7 & $\underline{68}$ & 2 & 0 & 1 & 1 & 0 & 1 \\
\hline & 3 & 3 & 14 & $\underline{55}$ & 4 & 3 & 0 & 0 & 1 \\
\hline & 4 & 1 & 1 & 16 & 57 & 3 & 0 & 1 & 1 \\
\hline & 5 & 1 & 1 & 6 & 30 & $\underline{40}$ & 1 & 0 & 1 \\
\hline & 6 & 1 & 0 & 0 & 6 & 32 & 36 & 5 & 0 \\
\hline & 7 & 1 & 2 & 1 & 4 & 7 & 28 & 33 & 4 \\
\hline & 8 & 0 & 0 & 1 & 4 & 4 & 7 & 38 & 26 \\
\hline
\end{tabular}




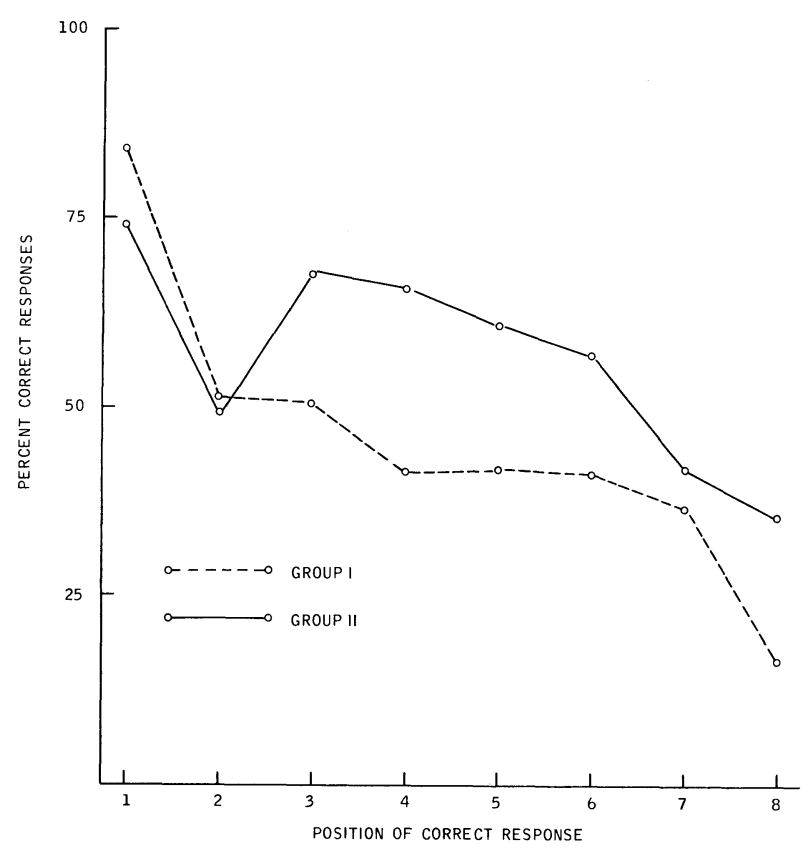

Fig. 2. Percentage frequency of correct second choice responses as a function of the position of the cue card.

dicating a fairly pronounced primacy effect. Why older subjects should display such an effect when young children do not is a question for further investigation.

The number of times each position was given as the first-choice response is presented in Table 1 for each of the eight correct positions. It can be seen that most of the errors, particularly for the high-numbered positions, consisted of selecting the card just one below the correct card. In fact Group I (the 4-year olds) made this type of error in positions 6,7 , and 8 more often than the correct response.

When the subject's initial response was incorrect (i.e., the card turned over did not match the cue card), he was required to make a second choice from the reduced set of cards; the probability of a correct second choice given that the cue card was actually in position $i$ is presented in Fig. 2. These second-choice probabilities are clearly greater than the chance level of $1 / 7$, and reflect the fact that $\mathrm{Ss}$ often made second choices very near in position to their first responses. Figure 3 shows the average response latencies for the first choice responses. It is evident that the latencies of the correct responses are faster than those of the errors.

\section{Diseussion}

The technique used in this study showed considerable success in maintaining the interest of the children. In our opinion, this is largely attributable to the fact that the Ss were permitted to keep trying when they made incorrect responses and thus were eventually correct on every trial. Each session lasted approximately 1/2 hour, and the Ss showed no signs of fatigue or lagging interest. More important, the data exhibit an orderli-

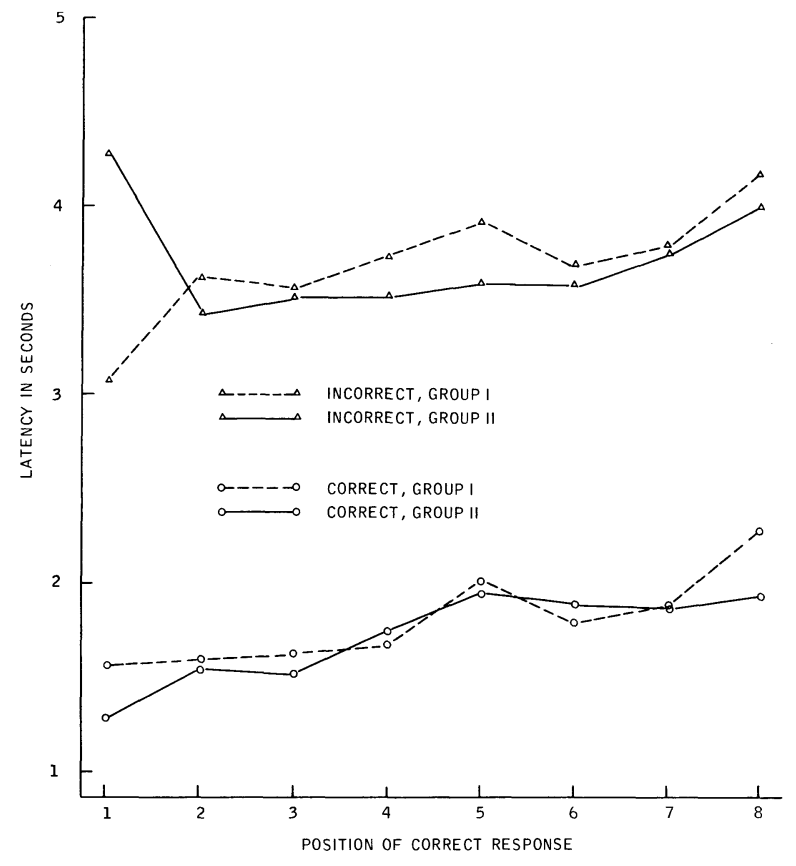

Fig. 3. Mean response latency as a function of the position of the cue card, for correct and incorrect responses.

ness which is usually difficult to obtain with children this young.

There are, however, some differences between this task and the paired-associate task typically used to study cued STM (e.g., Peterson \& Peterson, 1962). There are at least two ways to remember an item correctly in our experimental situation: (1) by direct association between a picture and a location on the table, and (2) by counting back from the most recent item and using interitem associations to determine how far back an item occurred. The frequent occurrence of responses that were one lower in position than the correct response seems to indicate that the latter type of process was at least partly in operation during this experiment; a simple response generalization hypothesis could not account for the very strong response bias found here. However, if Ss searched back through the list whenever a direct picture-location association was not available, the loss of some items due to forgetting would lead to a count that was too low, and thus to the bias effect found in the error data. The latency data give further support to this notion, since the extra time taken in the search process would be expected to increase the latency of an incorrect response.

\section{Referenees}

MELTON, A. W. Implications of short-term memory for a general theory of memory. J. verb. Learn. verb. Beh., 1963, 2, 1-21.

PETERSON, L. R. Immediate memory: Data and theory. In C. N. Cofer (Ed.), Verbal learning and behavior: Problems and processes. New York: McGraw-Hill, 1963.

PETERSON, L. R., \& PETERSON, M. J. Minimal paired-associate learning. J. exp. Psychol., 1962, 63, 521-527. 